Revista Temas Socio Jurídicos

Vol. 37 No 74 Enero - Junio de 2018

pp. $85-102$

ISSN: 0120-8578

ISSN electrónico: 2590-8901

\title{
LA QUIMERA DEL ESTADO EN LATINOAMÉRICA
}

\author{
Carlos Arturo Duarte Martínez ${ }^{1}$
}

Recibido: 2 de mayo de 2018

Aprobado: 31 de mayo de 2018

\section{RESUMEN}

En este escrito se analiza la configuración del Estado-nación, del Estado de derecho y del Estado social de derecho en Latinoamérica. Se demuestra que la adopción de estos modelos políticos, de raíz europea-occidental, no ha tenido en cuenta la realidad latinoamericana, de allí que ninguno de ellos haya tenido una validez real y completa, merced al modelo feudal de su vida colonial, al carácter autoritario, mesiánico, populista y vertical de sus gobernantes, a la debilidad fiscal y a una división internacional del trabajo de corte extractivista.

Palabras clave: Latinoamérica, poder público, Constitución, democracia.

\section{THE CHIMERA OF THE STATE IN LATIN AMERICA}

\begin{abstract}
This document analyzes the context-setting of the nation-state, the rule according to higher law, and the social rule of law in Latin America. It is demonstrated that the adoption of these political models of westernEuropean roots has not taken into account the Latin American reality, hence none of them has had a real and complete validity, due to the feudal

1 Abogado y especialista en Derecho público de la Universidad Autónoma de Bucaramanga (UNAB). Candidato a magíster en Derecho constitucional de la Universidad Éxternado de Colombia. Docente auxiliar y coordinador académico de la especialización en Derecho disciplinario de la UNAB. Empleado judicial en el Tribunal Administrativo de Santander. Correo: cduarte3@unab.edu.co
\end{abstract}


model of its colonial life, the rulers' authoritarian, messianic, populist, and vertical character, the fiscal weakness, and an international division of extractive labor.

Key words: Latin America, Public power, Constitution, Democracy.

\section{A QUIMERA DO ESTADO NA AMÉRICA LATINA}

\section{RESUMO}

Este artigo analisa a configuração do estado-nação, do estado de direito e do estado social do direito na América Latina. Mostra-se que a adoção desses modelos políticos, de origem europeu e ocidental, não leva em conta a realidade latino-americana, de modo que nenhum deles teve uma validade real e completa, graças ao modelo feudal de sua vida colonial, ao caráter autoritário, messiânico, populista e vertical de seus governantes, à fraqueza fiscal e a uma divisão internacional do trabalho extrativista.

Palavras chave: América Latina, poder público, Constituição, democracia.

\section{INTRODUCCIÓN}

En su discurso al recibir el Nobel de Literatura, García Márquez (1982), uno de los insignes representantes del boom latinoamericano, describe con crudeza la historia socio-política del subcontinente y reconoce que ella también es valorada en su galardón. Se da un golpe en el pecho y confiesa que, ante esa "realidad descomunal", en su oficio de escritor ha tenido que pedirle "muy poco a la imaginación, porque el desafío mayor para nosotros ha sido la insuficiencia de los recursos convencionales para hacer creíble nuestra vida". Se refiere a esa vida que ha maravillado a Europa a través de la novela, con la que se explaya el ser latinoamericano en el mundo, y que ha recogido cinco premios Nobel de literatura.

La misma fascinación despertó en los franceses, primero, y en los italianos, belgas y españoles, después, la llegada de los escarabajos de la montaña a las competencias ciclísticas europeas en los años ochenta. Ellos, inventores del ciclismo, no podían concebir que unas personas tan pequeñas y con piernas tan delgadas como agujas, pudieran escalar las cuestas de un hors catégorie con una relación que enlaza un piñón de 19 dientes. Los suyos, de anchas espaldas y gran altura, los debían seguir con piñones de 23 y 25 dientes. Pronto se dieron cuenta de que no se puede de otra manera, sin asfixiar las piernas, afrontar los Andes colombianos, cuyos puertos exigen esfuerzos sostenidos de más de una hora y media, y cuyas extensiones pueden duplicar y triplicar a los de los Alpes y Pirineos.

Estas referencias a aspectos propios de Latinoamérica, en temas universales 
como la literatura y el deporte, plantean un germen de duda sobre la forma de organización social llamada "Estado". Frente a este, según Tilly (1992), no vale una teoría universal, aunque se haya querido adoptar en la antigua América española, desde que el fuego de los mosquetes y el filo de las espadas la separó del Reino español y la lanzó a la vida republicana.

La idea de Estado en Latinoamérica ha sido construida desde los cánones europeos. Las figuras e instituciones estatales se han trasplantado a nuestros países sin considerar muy bien las propias vivencias. Sin embargo, es bien sabido que la realidad desborda las formas legales, por lo que bien puede preguntarse si existe Estado en Latinoamérica y si son las repúblicas latinoamericanas Estado-naciones, Estados de derecho y/o Estados sociales de derecho. Frente a una respuesta negativa, será preciso preguntarse entonces si existen elementos propios de las organizaciones políticas latinoamericanas y si serán estos tan fascinantes como sus escritores y ciclistas.

Para responder estas preguntas, primero se abordarán de manera sucinta -con el peligro de las generalizaciones-los fenómenos científicos, culturales, políticos, económicos y belicistas que formaron al Estado, al Estado de derecho y al Estado social de derecho en Europa. Luego, se evaluarán los que se han presentado en Latinoamérica para establecer si convergen o no con la experiencia europea.

\section{LUCES Y FUEGO EN EUROPA}

\subsection{El Estado-nación}

La cortina medieval que cubrió a Europa durante casi diez siglos empieza a caer con el surgimiento de las primeras universidades laicas que, apartadas de las abadías y las scholas catedralicias o episcopales, abren al conocimiento un horizonte alejado de los dogmas católicos. La reinterpretación de los griegos clásicos, cuya preservación se debe, paradójicamente, a dichos espacios religiosos, da lugar a tomar por extraños los argumentos de autoridad religiosos. Si bien el surgimiento de las primeras universidades medievales europeas coincide con el de la escolástica, será esta superada al surgir inquietudes acerca del conocimiento, principalmente de cómo acceder a él, si desde la experiencia o desde la razón.

De otra parte, personas que no trabajan la tierra empiezan a encargarse de comercializar los excedentes de producción, lo que no consumen quienes siembran, y surgen oficios para crear lo que la tierra no da. Con el tiempo, estas labores se hacen más complejas y, con ello, aparece la especulación, el acaparamiento y la acumulación de capital. El mercantilismo entra en auge. Además, la riqueza de los súbditos llama la atención de los reyes. La intervención del monarca en la economía se decanta por el recaudo de impuestos; así se hace más rico y fuerte, lo que le permite no depender de la nobleza para ejercer el poder y acudir a la guerra. Su poder no es 
ya nominal, sino $\mathrm{real}^{2}$. El rey puede financiar su ejército y así tener el monopolio efectivo de la fuerza (Naranjo, 2006).

La asunción de un poderío militar permite a los reyes dar unidad territorial a su reino. La guerra que pacifica el interior de los Estados da legitimidad al poder del monarca y abre las fronteras a nuevas conquistas: las Islas Canarias, Navarra y, finalmente, el nuevo mundo en el caso español. A la unidad política de territorios sigue, a fin de consolidar el Estado-nación, la unidad socio-cultural: los súbditos deben tener identidad religiosa, idiomática y cultural con el monarca, con lo que se diversifican las poblaciones, que antes estaban unidas por la iglesia católica. La razón de Estado lleva a destruir el orden medieval, de allí que para Bastida (2001):

La inauguración del Estado como institución plenamente independiente trajo consigo la introducción de un nuevo modo de concebir la política. El Estado es la negación de la ciudad de Dios [...]. El súbdito [...] se convierte en ciudadano y la relación mutua de protección y lealtad se transforma en el único fundamento que origina la sociedad. Al agustinismo político le sucede [...] el maquiavelismo, el realismo político. (p.29).

Así, el absolutismo monárquico desplaza los designios ciertos e inmutables del catolicismo como el fundamento de la unidad y obediencia al Estado y su Derecho positivo.

Todos estos cambios que trajo la existencia del Estado-nación confluyeron en el genovés Cristóbal Colón, quien, descreído del dogma católico de que la tierra es plana, con el interés de abrir nuevas rutas comerciales que permitieran el intercambio económico con oriente y financiado por el absolutismo español, descubre el "nuevo mundo". Con esto, se vincula América con la historia del mundo occidental (Vela, 2010).

\subsection{El Estado de derecho}

En Inglaterra, la integridad del territorio se alcanza pronto en el proceso de consolidación como Estado-nación, por obra de Alfredo El Grande. Sin embargo, solo Enrique VIII, miembro de la Dinastía Tudor, logra el monopolio de la fuerza, típico de un Estado-Nación, en un periodo en el que Inglaterra se desarrolla como potencia política y militar.

El capitalismo avanzó más rápido en tierras inglesas, gracias a la Revolución Industrial. El poder económico de los liberales ingleses se materializa paulatinamente en prerrogativas políticas y civiles: en el siglo XIII hacen firmar al monarca Juan Sin Tierra la Carta Magna, en el XIV logran ser escuchados en la Cámara de los Comunes y en el siglo XVII entran en guerra con la Corona, incluso llegan a juzgar y decapitar a Carlos I, su monarca. Tras el interregno de la Mancomunidad de Inglaterra y 
luego de la restauración de los Estuardo, el liberalismo inglés da el golpe definitivo al absolutismo al derrocar a Jacobo II, para luego establecer una monarquía parlamentaria con Guillermo de Orange, quien firmó la Bill of Rights (Pisarello, 2014).

Los procesos revolucionarios burgueses, que entrañan la tensión entre la autoridad y el individuo, logran a sangre y fuego erigir una esfera privada inaccesible para el Estado, que cobija con dignidad y derechos a las personas, como límites al poder púbico. Se afirma desde entonces que los intereses del Estado no pueden ir en contra de los del individuo; es más, los segundos deben determinar a los primeros. Al Estado le corresponde entonces velar por la seguridad de las personas y de sus bienes, defender el cumplimiento de los contratos entre los comerciantes, procurar una administración de justicia expedita y abstenerse de intervenir en materia económica, el culmen del liberalismo económico. Surge así el Estado de derecho; su seña, adicional al Estado-nación, es el control del ejercicio del poder público por medio de la ley, en donde esto se confía a una pluralidad de organismos. La idea del Estado de derecho se esparce por la Europa continental desde finales del siglo XVIII (Vela, 2015b).

La gran acumulación de dinero, que posibilita a los burgueses extraer el poder público de las monarquías, se da por la ética protestante. A través del trabajo, ahorro y enriquecimiento, la burguesía del norte de Europa incrementa su poder económico, mientras que el sur católico sigue, por un considerable tiempo, formas precarias de producción de riqueza (López, 1983). Asimismo, el liberalismo económico alcanza el poder con apoyo de la Ilustración, movimiento intelectual que promueve la defensa del individuo y su dignidad como límite al poder estatal, de modo que el ser humano pueda "hacer uso público de la propia razón en todos los terrenos" (Kant, 2012, p.9). Sumado a la erradicación de la arbitrariedad en el ejercicio del poder público, el resultado de este movimiento se sintetiza en el tránsito que se hace del individuo como un sujeto de deberes, al cual se le castiga por incumplirlos, a un sujeto titular de derechos. Esos derechos están representados por la ciudadanía, idea ilustrada que funda la Nación.

Cabe destacar que la Declaración de los derechos del hombre y del ciudadano, aprobada por la Asamblea Nacional Constituyente francesa en 1789, pieza fundamental de restricción del poder del Estado,

se construyó en torno a la consolidación del derecho de la propiedad como una estructura de derecho natural equiparable a la igualdad, libertad y la seguridad, pero ella sí, en todo caso, tangible y realizable, mientras que los otros derechos no eran más que manifestaciones exultantes de una quimera. (Gómez, p.21).

Esta prelación del derecho a la propiedad conduce a que se establezcan límites a otros derechos con fundamento en la amplitud del patrimonio de las personas, como el sufragio censitario. Con el tiempo, el fetiche a la autonomía de la voluntad, a la propiedad privada y al proceso legislativo 
estropea al Estado de derecho.

\subsection{Estado social de derecho}

Todo el siglo XIX fue un campo abierto para el capitalismo. La Revolución Industrial se consolida en toda Europa del norte y en los Estados Unidos de América. Pese al éxito económico, se presentan circunstancias no previstas cuando el liberalismo se propone como un modelo hacia la felicidad; las industrias, como medios de producción, caen en manos de muy pocos y, porque el consumo de bienes y servicios no alcanza un alto nivel que lleve a la economía a sostenerse por sí sola, la mano invisible no puede hacer ajustes automáticos para traducir en beneficio común la riqueza de los ciudadanos. Al capitalismo le siguieron la exclusión y las desigualdades (Vela, 2015b).

En este escenario, recuerda Vela (2012), Keynes y Heller plantean que es necesaria la intervención del Estado para poner a salvo de crisis el modelo económico capitalista, que no es perfecto, y para satisfacer las necesidades de los excluidos y desiguales, los más débiles en lo económico y social. Heller (2011) señala que ningún otro modelo económico ha creado tanta riqueza en la historia de la humanidad como el capitalismo, pero esa actividad económica hace desiguales a los hombres, de allí que la función estatal no se pueda disociar de la economía. Surge así el constitucionalismo social, que habilita la "intervención del Estado en esferas que hasta entonces le habían sido vedadas, como la producción económica, la organización de la empresa privada o simplemente el mercado de bienes y servicios" (Herrera, 2017, p.174).

La intervención del Estado en la economía implica sin duda una profundización de la democracia, en tanto ofrece nuevas garantías para la vigencia de una real ciudadanía. A lo público le interesan los problemas que puedan presentarse en los asuntos individuales de las personas excluidas de los beneficios del capitalismo. El Estado no solo asume la protección de los derechos civiles, sino la satisfacción de los derechos sociales. Aquí el individuo es visto no solo como titular de derechos sino también sujeto de necesidades que por sí mismo no puede satisfacer. Esos asuntos individuales que le niegan el disfrute de su dignidad humana resultan siendo interés del Estado.

En este orden de ideas, desde el inicio de la vida estatal se entiende que las personas no son iguales, algo que el Estado de derecho infravalora, puesto que la igualdad se predica a partir de la ley; es decir, la igualdad es supuesta y no real. Es por esto que el Estado social de derecho emprende como propósito lograr la igualdad material. En realidad, como resalta Bernal de Tugendhat (2008), " [e]s imperioso reconocer que el liberalismo presupone más individuos capaces de ser ciudadanos libres de los que existen en la práctica" (p.296).

Así, mientras la distinción de lo público y privado en el Estado de derecho 
se materializa para el ciudadano en derechos civiles y políticos, sobre todo en el derecho de propiedad, la configuración del Estado social de derecho conlleva el reconocimiento de derechos sociales que, asegurados en las Constituciones, son expresión del acuerdo democrático sobre "lo que es no decidible: [...] porque no puede ser no decidido" (Ferrajoli, 2004, p.275.). Es necesario tomar decisiones positivas para satisfacer dichos derechos, lo que genera "unos costos y esos costos se deben pagar de alguna forma, esa forma, en esencia, es a través de los impuestos" (Bateman et al, 2009, p.67).

Sin embargo, en la actualidad, el Estado social de derecho enfrenta fenómenos económicos que desdibujan su identidad garantista y conducen, como resalta Chevallier (2011), a redefinir las funciones estatales y a adoptar, en el ámbito del Derecho laboral, medidas "que buscan esencialmente retrasar la edad de jubilación, para prolongar el período de cotizaciones y reducir los pagos" (p.116). Pisarello (2014) advierte que esos cambios no pueden ser contenidos ni por

las teorías que postulan la prohibición de retrocesos en materia social, ni [por] las que defienden la existencia de un contenido esencial en los derechos democráticos que en ningún caso debe desnaturalizarse, ni [por] las que plantean, de modo más general, la existencia de líneas rojas que ninguna política de ajuste estructural debería traspasar. (pp.16-17).

Así, importantes cambios en la organización política estatal ocurren en la actualidad en occidente.

\section{LA IDEA DE ESTADO EN AMÉRICA LATINA}

\section{1. ¿La América española dentro del Estado-nación español?}

Nada indica que las colonias de España en América participaran en la formación y consolidación del Estado-nación español entre los siglos XV y XVIII. La vida de los criollos, nativos y africanos se desarrolla en condiciones diferentes a los que presentaba la metrópoli para los españoles. La América española no vive el mercantilismo en su plenitud merced a las fuertes restricciones impuestas por la corona desde la Casa de la Contratación de Indias. Se les obliga a comerciar sus productos solo con España y no directamente entre las colonias, lo que impide que sus gentes lleguen a acumular grandes riquezas. Las pequeñas mercaderías se agotan en el consumo interno; además, la dinámica del colonialismo lleva a que los principales productos de comercio que salen de las indias sean metales preciosos, los que, junto con los productos agrícolas de interés para Europa, son recogidos mediante la Flota de Indias. Estos viajes regulares permiten asegurar el monopolio de comercio implantado desde la Casa de Contratación de Indias y proteger el comercio de metales preciosos de piratas y corsarios (Ots y Capdequi, 1969). 
El principal objetivo de los gobernantes españoles en materia de política económica para las colonias es proteger la minería, de allí que impidieran el desarrollo industrial colonial. Por esto, "[s]e dificultó, en suma, por todos los medios el comercio directo entre unas comarcas y otras de los territorios coloniales, sobre todo cuando se trataba de artículos que pudieran hacer la competencia a los que España exportaba" (Ots y Capdequi, 1969, p.112). En síntesis, "Las indias fueron consideradas [...] como simple mercado completamente de la economía peninsular" (p.90).

Lo que sí tiene éxito en la economía colonial-española es el feudalismo por intermedio de las encomiendas y los resguardos indígenas. Nieto Arteta (1975) destaca que estas figuras demuestran la "unión de un poder político y la propiedad territorial [...] que es una institución feudal" (p.22). De otra parte, los conocimientos desarrollados por los imperios precolombinos que sucumben ante las oleadas de bandidos llegados de España son destruidos, y se imponen los dogmas católicos. En lo cultural, religioso y social, no hay articulación sino destrucción e imposición de los valores españoles.

En realidad, las colonias españolas son expresiones del poderío del Estado-nación español y no parte de él. Como indicó Mitre, citado por Ots y Capdequi (1969), "La América española no formaba cuerpo de nación con la Península, ni estaba ligada a ella sino por el vínculo de la corona" (p.344). Al nuevo mundo llega la barbarie como expresión de la civilización con el rótulo del colonialismo.

\subsection{La apuesta de las noveles repúblicas por ser Estados de derecho}

\subsubsection{Siglo XIX}

La falta de los elementos de Estado-nación que caracterizan a los países que surgen tras las guerras de independencia, peleadas por ejércitos independentistas, no por ejércitos nacionales, supuso para ellos múltiples contradicciones. Las jóvenes repúblicas resultan abocadas a la tarea de "construir el Estado antes de la nación y [...] extraer la nación del Estado" (Valencia, 2012, p.95). Sus líderes, como hijos de la Ilustración, con el propósito de seguir los ejemplos de los Estados Unidos de América y de la República francesa, abrazan la idea de constituir Estados de derecho; sin embargo, no hubo quien ejerciera un monopolio de la fuerza en los territorios liberados.

Esto condujo a que se presentaran proyectos monárquicos en la antigua América española. Agustín de Iturbide crea el Primer Imperio Mexicano, que se extiende desde la alta California, Nuevo México y Texas, en el norte, hasta Costa Rica, al sur, hasta sus límites con la Gran Colombia. Este régimen monárquico, que se funda en tres garantías (religión, independencia y unión) no dura ni un año. Iturbide no pudo legitimar su poder. 
En el sur, consciente de la necesidad de establecer un orden político, Bolívar propuso, primero ante el Congreso de Angostura y luego en Bolivia, un régimen constitucional autoritario, con rasgos monárquicos inclusive. Esta fue una respuesta a la asunción por parte de Bolívar de una "tarea mesiánica con relación a las colonias hispanoamericanas: la fundación de una república disciplinada y virtuosa, calcada sobre el modelo romano, en los Andes sudamericanos" (Valencia, 2012, pp.101102). Sabía que en los primeros años de las República colombiana era necesaria más autoridad que libertad.

Estos primeros intentos de lograr el monopolio de la fuerza resultaron infructuosos, puesto que los impulsos de los diferentes actores políticos llevaron a la desintegración de esos Estados. De esos proyectos imperiales surgen múltiples repúblicas. Debe aclararse que en el proceso independentista de las colonias españolas también está presente la Ilustración. Sin embargo, en punto de verdad, los líderes de las noveles repúblicas

se vieron obligados a adoptar el arquetipo liberal de régimen constitucional puesto que el mercado de ideas de comienzos del siglo XIX no ofrecía opción distinta de la democracia representativa si de asegurar dominación y hegemonía en el espacio nacional se trataba. (Valencia, 2012, p.86).

Así, al adoptarse la Ilustración por fama y no por total convicción, la tarea de construir Estados de derecho en Latinoamérica durante todo el siglo XIX y bien entrado del siglo XX resulta infructuosa en tanto el ámbito político no obliga a buscar un proceso de construcción de Estado, de respeto a lo individual y de distinción con lo público.

El presidencialismo como régimen de gobierno es importado por las jóvenes repúblicas, siguiendo los ímpetus norteamericanos. Sin embargo, nunca se consolida debido a los intereses disímiles de las oligarquías; la inestabilidad política generó presidentes fuertes y cámaras legislativas débiles, sin capacidad ni oportunidad para ejercer controles (Carpizo, 2009). El presidencialismo en Latinoamérica fracasa debido también a la presencia de proyectos personalísimos, mesiánicos y caudillistas de "hombres providenciales"; a algunos de ellos, García Márquez (1982) se refiere en La soledad de América latina. Las más enconadas discusiones políticas se deciden en los campos de batalla: el ejercicio de la política exige saber del oficio militar. Las tensiones latinoamericanas producen que se agregue el sufijo -ista al régimen presidencial, lo que perdura hasta hoy.

Por su parte, el liberalismo económico también tiene traspiés en su recepción latinoamericana. Los procesos socioeconómicos de los países de la antigua América española no pueden romper los lazos del modelo feudal: la tierra sigue siendo la principal fuente de riqueza y, por muchos años, es explotada por personas no libres. La luchada apertura de los mercados, en búsqueda de un comercio vivo y sin restricciones por los 
liberales, aumenta los márgenes de desigualdad en las sociedades. Las nuevas repúblicas asisten desde un comienzo al concierto internacional sin herramientas para competir activamente y tener posibilidades de generar riqueza para sus gentes, de modo que puedan hacerse fuertes ante el autoritarismo desbordado de los gobernantes a fin de limitar el ejercicio del poder público (Vela, 2012). Por ejemplo, al finalizar la guerra de independencia, los colombianos eran dueños de 16 barcos mercantes $\mathrm{y}$, un quinquenio más tarde, se aumenta la flota en 46 barcos, ninguno capaz de atravesar los océanos (Gaviria, 2012).

Los propósitos de libertad económica sirvieron al capital extranjero, cuyos deudores son, entre otros, las repúblicas hispanoamericanas; desde entonces, no duda en invadir y bloquear a algunos países latinoamericanos para proteger los intereses de sus nacionales o incluso forzar el pago de sus acreencias. Bien dijo López (1983):

El siglo XIX lo gastarán nuestras nacionalidades tratando de realizar vanamente el ideal del Estado gendarme, impasible ante los fenómenos de la vida económica, indiferente a la suerte de los indios, obligado a satisfacer apenas en la medida de sus recursos las más apremiantes necesidades colectivas, sin un criterio profundo de servicio público, ni un alto sentido histórico de la conservación de los valores nacionales ni de defensa de la integridad territorial de nuestro Estado, mientras la burguesía de las ciudades vivía planteando a los gobiernos por medio de los parlamentos el clásico dilema: o someterse o dimitir. (p.283).

En este contexto político y económico una limitación del poder en garantía de los derechos y libertades de los ciudadanos es un auténtico delirio, por lo que el autoritarismo prima sobre las garantías jurídicas.

\subsubsection{El siglo $\mathrm{XX}$}

La aplicación del capitalismo como modelo económico mundial profundiza la repartición internacional del trabajo entre países del norte y del sur. Si bien en estos últimos empiezan a surgir las industrias, son pequeñas, sectorizadas y sus productos no pueden competir en calidad y cantidad con los del norte. Nunca se da una verdadera revolución industrial: el proceso de industrialización camina a pasos pequeños (Vela, 2015b).

Puede decirse que las relaciones de dependencia de los países latinoamericanos, respecto del primer mundo, no se eliminan sino se transforman luego de la colonia. Al antiguo colonialismo se agregó el prefijo neo- como signo de la nueva relación imperial entre Europa y América latina; en esta, se reconoce la autonomía jurídica de los nuevos Estados, pero se ata su precaria soberanía en lo político a la imposición de formas de organización o de gobiernos y, en lo económico, a la "ayuda" o "cooperación internacional", como manifestación de dependencia nacional (Díaz, 1997).

Sin que el capitalismo se aplique por completo en Latinoamérica, la 
explotación de la tierra sigue teniendo un gran preso y la riqueza no se genera para todos los sectores. Las élites ricas no van a impulsar, en términos políticos, el reconocimiento de más derechos y libertades, ni a crear una distinción equilibrada entre lo público y lo privado. Frente a las pretensiones de extraer a las élites del poder público, estas prefieren, en lugar de una apertura transformadora del estamento social, los convenientes gobiernos militares que concentran el poder y la autoridad $\mathrm{y}$, con ello, conservan el statuo quo señorial heredado de la colonia. En el siglo XX, los intentos de distinguir el poder civil del militar ceden el paso a la intervención de los militares en la política. Las dictaduras militares cunden a lo largo de Latinoamérica. Como señala el profesor Díaz (1997), en este escenario "[e]l poder se concentra y se incrementa, pero las libertades (derechos individuales) se reducen y limitan y los derechos sociales [...] sólo cubren a una minoría de la población” (p.97). Las dictaduras militares llevan al exilio a muchos escritores, quienes salen a conocer el mundo que conquistan tiempo después.

Estos problemas del liberalismo y de la democracia generan movimientos que abrazan la lucha armada con la idea de imponer regímenes socialistas. Los resultados son dictaduras más fuertes, más restrictivas de los derechos. Cualquier límite distintivo entre una esfera pública y privada es desconocido frente a los sectores populares, de modo que la esfera pública se superpone a la esfera privada. Pocos de estos movimientos insurgentes logran llegar al poder, pero otros más sí ponen en duda el precario monopolio del poder de los Estados latinoamericanos.

Si hay un momento histórico en que los regímenes políticos latinoamericanos se han encontrado lejos de ser Estados de derecho es este: el ejercicio del poder no tiene límites. Desbordadas, las autoridades cometieron acciones violatorias de los derechos de las personas para mantener los beneficios que el subdesarrollo trajo para las clases sociales privilegiadas.

\subsection{Estado social de derecho}

Sin que en América latina el capitalismo tuviera el éxito económico e industrial vivido en Europa y Estados Unidos, sí recoge sus peores consecuencias. La apuesta para hacer frente a los nuevos problemas, sin solución a los que ya existían, consistió, nuevamente, en copiar. A finales de los años ochenta y a lo largo de los años noventa, se da una serie de reformas en las constituciones de Latinoamérica, en las que se consagra la cláusula del Estado social de derecho. Se piensa que, si los países de Europa occidental, en su tránsito hacia la democracia después de las caídas de los regímenes totalitarios (fascismo, nazismo, franquismo o salazarismo), derivaron en la consagración de Estados sociales del derecho, lo mismo vale para que Latinoamérica salga de los oscuros regímenes militares y dictatoriales. Sin embargo, esto no ha sido posible, debido a que los procesos democráticos que exige ser un Estado social de derecho han encontrado diferentes límites. 
En primer lugar, en el plano político valen varias aclaraciones. Como ha señalado Boeckh (2009) "es importante dejar de mezclar los procesos de paz con los esfuerzos de democratización” (p.49). Los acuerdos de paz se producen entre élites que tienen un alto grado de control sobre su base social. Los acuerdos políticos, que superan la Revolución mexicana, la Violencia en Colombia y las guerras de Centroamérica, no conducen a transformaciones democráticas.

El Estado social de derecho es un escenario apropiado para recibir y dar respuesta a demandas democráticas, elevadas por sectores excluidos -por lo que representa una pretensión igualitaria- y enfrentadas a sistemas políticos con alto grado de exclusión y privación. Sin embargo, las demandas democráticas en Latinoamérica resultan enfrentadas a regímenes populistas. El populismo, según Laclau (2005), asume una lógica política y un lenguaje de discurso que es impreciso y fluctuante, de modo que no puede determinar con claridad las demandas que va a abarcar y a excluir, a lo que se llega debido a que el sistema social en el que surge es heterogéneo, desarticulado y fluctuante. La misma realidad latinoamericana es la cruz de sus gentes. El populismo asume una demanda popular, "con una centralidad inesperada y se vuelve el nombre de algo que la excede, de algo que no puede controlar por sí misma y que no obstante se convierte en un destino al que no puede escapar" (Laclau, 2005, p.151).

En Ecuador, por ejemplo, la neoliberalización de la economía generó protestas de la sociedad civil para participar en el debate público, a fin de introducir asuntos excluidos, cuestionar temas que se asumen implícitos y lograr una democracia participativa con descentralización administrativa como herramienta de autogobierno democrático. Aquellos movimientos rompen la hegemonía liberal, no se enmarcan en la teoría de la democracia liberal y buscan cambiar las instituciones que sustentan los procedimientos del Estado de derecho. Sin embargo, el Gobierno de Rafael Correa, con el que se dilapida el neoliberalismo en Ecuador, no desarrolla del todo ese movimiento social destacado y genera un "otro institucionalizado" cuyas demandas no son tenidas en cuenta (Andrade, 2009).

En Venezuela, se planeó seguir hacia el socialismo en paz. Se enarboló la democracia participativa como escenario para la toma de las decisiones públicas más importantes, lo que tuvo por un tiempo relativo éxito en cuanto a los resultados, pero fracasó cuando la renta petrolera se redujo y sus procedimientos electorales resultaron deficientes para la toma de decisiones públicas. Venezuela con Chávez cae en una suerte de "autoritarismo electoral", debido a que, si bien se convoca al pueblo a elecciones y comicios, dichos escenarios son manipulados por el régimen populista, en detrimento de los derechos civiles y políticos (Marquéz, 2009). Ya con Maduro el sistema político venezolano es incapaz de sostenerse ante el conflicto institucional generado entre el Gobierno chavista y la Asamblea Nacional de mayoría opositora, como consecuencia de la típica ausencia de "válvulas de escape" del hiperpresidencialismo 
latinoamericano.

En Colombia, el último país latinoamericano que tuvo un conflicto armado interno, se ha apostado por lograr un completo control territorial por parte del Estado sobre las guerrillas comunistas, como factor de consolidación. Dicho propósito estuvo mediado por el autoritarismo, el populismo y la autocracia de un presidente como Álvaro Uribe, quien promovió la deslegitimación de las guerrillas al mostrarlas sin ningún compromiso político y con un fin de acumulación económica, fundado en el narcotráfico, con quienes solo vale la pena entrar en guerra total (Donato, 2010). En dicha empresa se valió de su carisma y una retórica mesiánica para identificar al enemigo de la seguridad del Estado, a saber, todo aquel que no lo siga (Castro, 2010). Al eliminar cualquier naturaleza política de ese enemigo, sea armado o civil, se presencia una lucha en contra de simples delincuentes comunes; esto, sumado a la violación de los derechos humanos y al notable desinterés de la satisfacción de los derechos sociales.

Como advierten Espinosa \& García (2013), todo este proceso no ayudó a consolidar la presencia del Estado en el territorio, como tampoco a garantizar los derechos de sus habitantes, pues la institucionalidad estatal sigue siendo débil, debido a que en los territorios "recuperados" por la política de la seguridad democrática la intervención militar no ha sido seguida por el establecimiento de autoridades locales con márgenes de actuación, ni el disfrute de unas contiendas electorales libres, ni la existencia de jueces y órganos de control fuertes. Por el contrario, dichos escenarios institucionales han sido cooptados por el clientelismo (incluso armado, a partir de reductos o grupúsculos de no desmovilizados) y las élites locales.

Asimismo, la tensión entre seguridad del Estado y libertad se presenta en otros países latinoamericanos debido al surgimiento de fuertes grupos de narcotraficantes que ponen en jaque a los Estados en el monopolio efectivo de la fuerza.

En segunda instancia, en el plano económico, la tardía consagración del Estado social de derecho, en donde ciertos aspectos de lo privado vuelven a ser públicos, coincide con la entrada del neoliberalismo como doctrina económica impuesta desde el primer mundo, respuesta a la recesión inflacionaria de los años setenta y que exige privatización, desregularización y globalización de lo económico (Díaz, 1997) Si bien esto último no ha llevado a la desaparición del Estado, los institutos propios del Estado social de derecho no han podido atacar con fuerza suficiente los problemas de desigualdad socioeconómica para satisfacer el nuevo catálogo de derechos sociales y así dar plena vigencia a la dignidad humana.

Esta situación ha generado discrepancias entre los elementos ideológicosocial y material-neoliberal del novo modelo estatal, lo que de por sí demuestra cierta vigencia del Estado social de derecho, que, en todo 
caso, aún no puede plantarse como la parte fuerte en dicha tensión, capaz de resolverla a su favor. Es así debido a que el neoliberalismo en Latinoamérica se asume como la "ideología imperante del capitalismo en su fase económica” (Díaz, 1997, p.510) que ha traído beneficios a los mismos sectores minoritarios privilegiados.

Velasco (2007) apunta al respecto que el problema de distribución de la riqueza en Latinoamérica parte esencialmente de la tensión que surge entre el fundamento político y el económico de los Estados y sociedades modernas; esto es, entre la democracia y el capitalismo. Esta tensión genera consecuencias gravosas en las sociedades latinoamericanas, puesto que no son homogéneas ni igualitarias.

Lo anterior tiende a persistir porque:

la carga tributaria en América Latina es notablemente baja, incluso comparada con la de países en igual nivel de desarrollo [...] [1] a debilidad fiscal del Estado limita su capacidad para mantener la ley, proveer canales para la participación democrática, atender las demandas sociales y promover el desarrollo económico. (Velasco. 2007, pp.136-137).

Es difícil cambiar este escenario, puesto que los medios formales democráticos de la región no tienen el alcance de interferir "con la desigual distribución del poder socioeconómico”, el cual es detentado por las élites económicas.

Para hacer compatibles la democracia y el capitalismo en Latinoamérica, Velasco (2007) propone dar dos pasos: primero, "liberarse de la ilusión de que la democracia es sólo o predominantemente un asunto de procedimientos", lo que implica reconocer que ella tiene una dimensión sustancial además de la formal, que impone límites y exigencias básicas al Estado y a la sociedad para una real vigencia de los derechos. Segundo, "diseñar propuestas redistributivas y estudiar sus condiciones de posibilidad"; esto es, intervenir efectivamente en la economía, aumentando la carga tributaria entre los más capaces en términos económicos. Tercero, sin recursos financieros difícilmente se podrá satisfacer los derechos sociales, por lo que es necesario adoptar "un modelo más equitativo de desarrollo económico”, que priorice no el gran capital, sino el pequeño elemento productivo de la sociedad. El Estado debe preocuparse por influir positivamente en la creación de riqueza de los pobres y desiguales.

\section{4. ¿Hacia una propia identidad?}

El siglo XXI trajo la expedición de la Constitución venezolana de 1999, ecuatoriana de 2008 y boliviana de 2009, que se caracterizan, según Pisarello (2011) por: activar el poder constituyente a través de movilizaciones populares; consagrar mecanismos de democracia directa; adoptar un neopresidencialimo, con un marcado carácter reeleccionista que opera en detrimento del poder legislativo; prever un catálogo de 
derechos fundamentales, con previsiones ajenas a la tradición occidental, en el que se hace un reconocimiento expreso a los valores indígenas y a los derechos de la naturaleza; establecer la tutela judicial de todos los derechos; regular modelos de "economía social "solidaria" y "plural" con una activa intervención del Estado; prohibir "ejercicios antisociales del derecho de propiedad"; empoderar a los sectores populares y movimientos sociales y atenuar la influencia de las castas oligárquicas. Sin embargo, la práctica constitucional se ha caracterizado por reconocer un papel importante a las fuerzas militares en la resolución de los conflictos sociales, promover un ejercicio centralista, personalista y vertical del poder y no romper la división internacional del trabajo de sentido extractivita para Latinoamérica.

Las anteriores son las primeras manifestaciones identitarias de Latinoamérica en el fenómeno del constitucionalismo; sin embargo, su declive podría seguir al de los movimientos políticos populares que las generaron.

\section{CONCLUSIONES}

Como quedó expuesto, la vida colonial bajo dominio español no permitió a los latinoamericanos vivir en un Estado-nación. El absolutismo de la Monarquía española los hizo sujetos a un proceso de expansión y consolidación, pero no de integración. En lo económico los expuso a un régimen feudal y de explotación de materias primas en las que la riqueza no se quedaba en el nuevo mundo. Las identidades de los pueblo conquistados fue eliminada bajo la idea de la supremacía del ser europeo y su credo católico. Por ello, el fenómeno de ruptura de las colonias españolas respecto de la metrópoli no se enmarca como el paso de un antiguo Estado-nación a otro nuevo.

Desde entonces, los políticos que han ejercido el poder público han caminado por causes erróneos a fin de lograr el monopolio de poder y su ejercicio legítimo. El siglo XIX estuvo lleno de hombres providenciales, cuyos proyectos fracasaron uno tras otro a causa de sucesivas guerras en las que fueron incapaces de transformar el pasado colonial de sus territorios. El siglo XX fue encarado por un similar autoritarismo a través de dictaduras militares que respondían a intereses de las clases dominantes en contra de los ímpetus populares de trazar una gruesa línea entre lo público y lo privado y a través de gobiernos populistas en donde resulta indeleble la representación de otro u otros excluidos. El autoritarismo de los populistas no se logra mediante las armas, sino con la imposición de una supuesta voz mayoritaria que acalla a las minorías.

En lo económico la vida republicana de los Estados ha residido principalmente en la tenencia de la tierra y el modo colonial se ha perpetuado a través de sistemas de extracción de su producción y recursos naturales. La acumulación capitalista en Latinoamérica no ha sido un camino a la libertad, ni el lazo con el que se pone límites al ejercicio del poder público. 
Participar en el mercado mundial capitalista, con un exiguo desarrollo industrial no ha hecho más que generar conflictos sociales, de gentes con necesidades insatisfechas que exigen mejores condiciones en términos de democracia y derechos, en medio de un auténtico neocolonialismo. La división del trabajo internacional, en donde Latinoamérica no percibe la mayor riqueza.

Además, la poca riqueza que se produce en estas tierras está mal distribuida, ante una organización estatal que no tiene los medios necesarios para satisfacer las aspiraciones de los derechos del Estado social. En medio de una tensión entre lo material y lo ideológico, entre lo económico y lo político, la pobreza no se reduce y la deuda externa aumenta. Como dice el profesor Vela (2015a),

Con la internacionalización de la economía de mercado [...] se expandieron las ideas de un liberalismo sin fronteras que fortalecieron la interdependencia económica, pero que [...] promovieron el declive de las instituciones estatales reguladoras de las finanzas, el comercio y del trabajo. (p.47).

Así, la actividad estatal en materia económica no ha sido eficaz en potencializar el bienestar social en el mejor sentido posible: que los excluidos del capitalismo no sean muchos. Los movimientos populares que intentaron romper ese modelo sistema económico están, además, de salida. Todo esto lleva a que, sin duda, los modelos de Estado no sean más que una quimera, un sueño de algunos que no ha podido ser realidad y un instrumento de otros que han sabido estructurar un orden político violento y sin límites, protector de los pocos propietarios de la riqueza, que valora lo europeo y elimina lo indígena, y que ha hecho hasta lo inimaginable para no cambiar. Desde luego, el orden político existente en Latinoamérica dista del lujo de sus escritores y ciclistas.

\section{REFERENCIAS}

Andrade, P. (2009). La experiencia de democratización en Ecuador durante la era neoliberal. En Márquez, M. L. (Ed.), Democracia y ciudadanía. Bogotá: Universidad Pontificia Javeriana.

Bastida, X. (2001). El silencio del emperador. Bogotá: Universidad Nacional de Colombia.

Bateman, A., López, J., López, J. Vengoechea, J. (2009). La garantía de los derechos sociales. Bogotá: Pontificia Universidad Javeriana \& Grupo Editorial Ibáñez.

Bernal, C. (2008). Fundamento, concepto y estructura de los derechos sociales. En El Derecho de los derechos. Bogotá: Universidad Externado de Colombia.

Boeckh, A. (2009). Guerra democracia y paz: algunas consideraciones 
preliminares. En Márquez, M. L. (Ed.), Democracia y ciudadanía. Bogotá: Universidad Pontificia Javeriana.

Carpizo, J. (2009). Características esenciales del sistema presidencial e influencias para su instauración en América Latina. En Concepto de Democracia y sistema de gobierno en América Latina (pp.1-34). Bogotá: Universidad Externado de Colombia y Universidad Nacional Autónoma de México.

Castro, E. (2010). Tendencias autoritarias de la democracia colombiana. En Ángel, J. (Ed.), Problemas de la filosofía, la política y la argumentación jurídica (pp.155-152). Bogotá: Universidad Libre.

Chevallier, J. (2011). El Estado posmoderno. Bogotá: Universidad Externado de Colombia.

Díaz, P. (1997). Estado y tercer mundo. Bogotá: Temis.

Donato, Ó. (2010). Estado y revolución: el schmittiaismo conceptual de Uribe. En Ángel, J. (Ed.), Problemas de la filosofía, la política y la argumentación jurídica (pp.125-134). Bogotá: Universidad Libre.

Espinosa, J. y García, M. (2013). El derecho al estado. Los efectos legales del apartheid institucional en Colombia. Bogotá: Dejusticia.

Ferrajoli, L. (2004). Juspositivismo crítico y democracia constitucional. En Epistemología jurídica y garantismo (pp.265-282). México D.F.: Fontamara.

García Márquez, G. (1982). La soledad de América Latina. Recuperado de http://cultura.elpais.com/cultura/2014/04/03/ actualidad/1396552129_445979.html

Gaviria, E. (2012). El reconocimiento de nuestra independencia y los intereses mercantiles anglosajones. En Barbosa, F. (Ed.), Historia del Derecho público en Colombia (pp.479-419). Bogotá: Universidad Externado de Colombia.

Gómez, L. (2008). Teorías de los derechos fundamentales. Bogotá: Doctrina y Ley.

Heller, H. (2011). Teoría del Estado. México D.F.: Fondo de Cultura Económica.

Herrera, C. (2017). Confines del constitucionalismo. Bogotá: Universidad Externado de Colombia.

Kant, I. (2012). Contestación a la pregunta: ¿Qué es la ilustración? México D.F.: Taurus. 
Laclau, E. (2005). La razón populista. Buenos Aires: Fondo de Cultura Social.

López, A. (1983). Introducción al estudio de la Constitución de Colombia. Bogotá: Universidad Santo Tomás.

Márquez, M. L. (2009). La democracia en el socialismo del siglo XXI en Venezuela. En Márquez, M. L. (Ed.), Democracia y ciudadanía. Bogotá: Universidad Pontificia Javeriana.

Naranjo, V. (2006). Teoría constitucional e instituciones políticas. Bogotá: Temis.

Nieto Arteta, L. (1975). Economía y cultura en la historia de Colombia. Bogotá: Ediciones Tiempo Presente.

Ots y Capdequi, J. (1969). Historia del Derecho español en América y del Derecho indiano. Madrid: Aguilar.

Pisarello, G. (2011). Un largo Termidor: La ofensiva del constitucionalismo democrático. Madrid: Trotta.

Pisarello, G. (2014). Procesos constituyentes: Caminos para la ruptura democrática. Madrid: Trotta.

Tilly, C. (1992). Coerción, capital y los estados europeos (990-1990). Madrid: Alianza Editorial.

Valencia, H. (2012). Cartas de Batalla. Bogotá: Panamericana.

Vela, B. (2010). Contribución al debate sobre la formación del Estado en colombiano en el siglo XIX. Bogotá: Universidad Externado de Colombia.

Vela, B. (2012). Una aproximación crítica al debate sobre la intervención del Estado en la economía en Colombia. En Barbosa, F. (Ed.), Historia del Derecho público en Colombia (pp.55-104). Bogotá: Universidad Externado de Colombia.

Vela, B. (2015a). Algunos elementos para el análisis del orden político en los países latinoamericanos. No publicado.

Vela, B. (2015b). Colombia no es una isla. Una contribución al debate sobre la formación del Estado colombiano en el entorno global. Bogotá: Universidad Externado de Colombia.

Velasco, J. L. (2007). Democratización y conflictos distributivos en América Latina. En Ansaldi, W. (Dir.). La democracia en América Latina, un barco a la deriva (pp.131-153). Buenos Aires: Fondo de Cultura Económica. 